*Proceedings*

\title{
Polyelectrolyte Multilayer Thin Films Assembled Using Poly(N,N-dimethylaminoethyl methacrylate) and Polysaccharides: Versatile Platforms towards Protein Immobilization, Sorption of Organic Pollutants and Synthesis of Silver Nanoparticles ${ }^{\dagger}$
}

\author{
Claudiu-Augustin Ghiorghita * and Ecaterina Stela Dragan \\ "Petru Poni” Institute of Macromolecular Chemistry, Grigore Ghica Voda Alley 41A, 700487 Iasi, Romania; \\ email1@gmail.com (C.-A.G.); sdragan@icmpp.ro (E.S.D.) \\ * Correspondence: claudiu.ghiorghita@icmpp.ro; Tel.: +40-232-217-454 \\ + Presented at the First International Conference on “Green" Polymer Materials 2020, 5-25 November 2020; \\ Available online: https://cgpm2020.sciforum.net/.
}

Published: 3 November 2020

\begin{abstract}
Coating of solid materials with polyelectrolyte multilayer films by the Layer-by-Layer (LbL) assembly strategy is one of the most versatile approaches to fabricate functional surfaces for a wide range of applications. In this contribution, the functionalization of silica microparticles with various $\mathrm{LbL}$ films containing poly $(\mathrm{N}, \mathrm{N}$-dimethylaminoethyl methacrylate $)$ and polysaccharides (sodium alginate, carboxymethyl cellulose and chitosan) is investigated. All polymers used in this work are biocompatible, while the deposition strategy is environmentally benign and allows a precise control of the outer layer properties (chemical nature, charge, roughness, etc.). The application of the obtained films in immobilization of proteins/enzymes (i.e., pepsin, bovine serum albumin, hemoglobin and lysozyme), sorption of organic dyes (i.e., methylene blue, methyl orange, bromocresol green and Congo red), as well as their use as "green" catalysts for the synthesis of silver nanoparticles was investigated as a function of the films' composition, the number of deposited layers and the assembly conditions ( $\mathrm{pH}$, ionic strength and polyelectrolyte concentration).
\end{abstract}

Keywords: Layer-by-Layer assembly; sorption/release; proteins/enzymes; organic dyes; silver nanoparticles

\section{Introduction}

The interaction of materials with surrounding media is controlled by their surface physical and chemical properties. Hence, intense efforts are devoted nowadays toward the functionalization of materials with thin organic coatings having controlled physical properties and specific chemical composition. One of the most attractive methods, which remarks itself by a precice control of used constituents and by nanoscale organization of the obtained films, is the Layer-by-Layer (LbL) assembly strategy [1]. The obtained thin organic films, denoted as polyelectrolyte multilayers, have been investigated for various potential applications, such as drug delivery, antibacterial coatings, tissue engineering, membrane separation/purification, etc., [2-5]. A common ground for all these applications consist in understanding the way LbL films interact with molecules from their surroundings.

Consequently, in this contribution the construction of some new LbL films consisting of the synthetic polycation poly(N,N-dimethylaminoethyl methacrylate) (pristine-PDMAEMA and 
quaternized with benzyl chloride-qPDMAEMA) and various polysaccharides (chitosan-CHI, sodium alginate-SA and carboxymethyl cellulose-CMC) is investigated [6-8]. The interaction of the obtained multilayers with proteins/enzymes, organic dyes and $\mathrm{AgNO}_{3}$ is studied. The aim of this work is to provide a comprehensive view on the way how similar LbL matrices interact with different types of molecules and ions from their surroundings.

\section{Experiments}

\subsection{Materials}

Pristine poly(N,N-dimethylaminoethyl methacrylate) (PDMAEMA, $\mathrm{M}_{\mathrm{w}}=50 \mathrm{kDa}$ and $85 \mathrm{kDa}$ ) and PDMAEMA quaternized with benzyl chloride (qPDMAEMA, $\mathrm{M}_{\mathrm{w}}=60 \mathrm{kDa}$, quaternization degree $=50 \%$ ) were synthesized according to a procedure presented in a previous work [9]. $\mathrm{CHI}$ (average $\mathrm{Mw}=207 \mathrm{kDa}$; deacetylation degree $=85 \%$ ), SA (Product code: 180947) and CMC (average $\mathrm{Mw}=90 \mathrm{kDa} ; 0.7$ carboxymethyl groups per anhydroglucose unit) were purchased from SigmaAldrich and used as received. The chemical structures of all the polymers used in this work are presented in Figure 1.<smiles>CC(C)(C)C(=O)OC1CCCCC1(C)C</smiles>

PDMAEMA

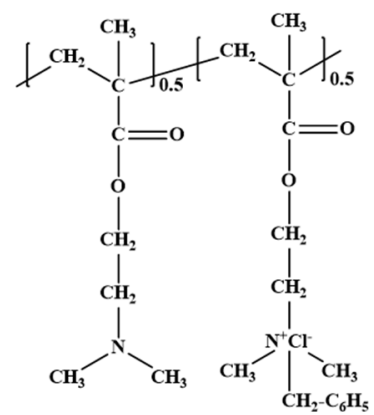

qPDMAEMA

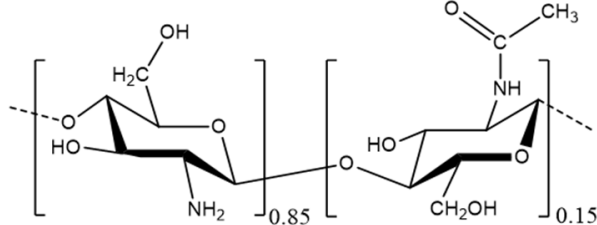

CHI

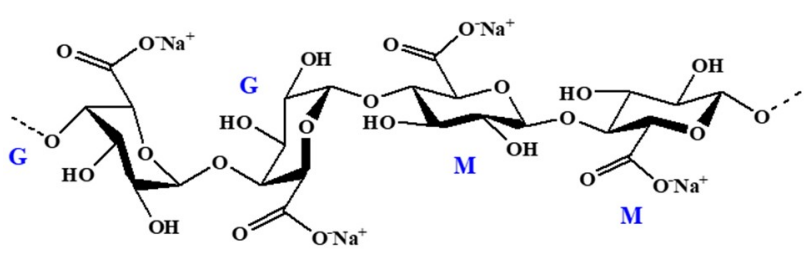

SA

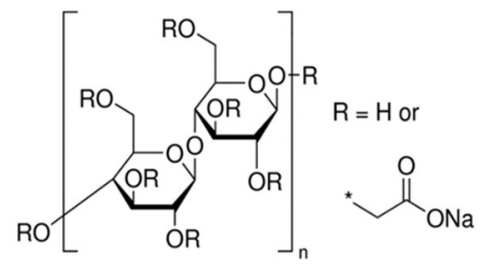

CMC

Figure 1. The chemical structures of PDMAEMA, qPDMAEMA, CHI, SA and CMC.

Spherical silica microparticles (SP1000, average diameter of 40-60 $\mu \mathrm{m}$ ) were purchased from Daiso Co. (Japan). Pepsin (PEP), bovine serum albumin (BSA), haemoglobin (HEM) and lysozyme (LYS) were purchased from Sigma-Aldrich and were used as received. Methylene blue (MB), methylorange (MO), bromocresol green (BCG) and Congo red (CR) were purchased from Sigma and used as received. $\mathrm{AgNO}_{3}$ and $\alpha, \alpha^{\prime}$-dichloro- $p$-xylene (DCX) were purchased from Merck and Fluka, respectively. Millipore grade water with a conductivity of $0.055 \mu \mathrm{S} / \mathrm{m}$ was used throughout all experiments. 


\subsection{LbL Deposition on Silica Microparticles}

The following LbL architectures were fabricated on silica microparticles: (i) (PDMAEMA/SA)n, (ii) (PDMAEMA/CMC) n and (iii) $\mathrm{CHI} / \mathrm{CMC} / \mathrm{qPDMAEMA} / \mathrm{CMC} / \mathrm{CHI}$, where PDMAEMA, pPDMAEMA and CHI are polycations, while SA and CMC are polyanions. In a typical synthetic procedure, $4 \mathrm{~g}$ of silica microparticles were first dispersed in $200 \mathrm{~mL}$ of polycation solution, and gently shaken for $60 \mathrm{~min}$ to allow surface saturation with polymer chains, and then washed three times with water to remove the weakly attached ones. Then, obtained composite microparticles were dispersed in the polyanion solution and gently shaken for $60 \mathrm{~min}$ to allow surface saturation, following three washing steps with water to remove the weakly attached chains. Polycation deposition/washing/polyanion deposition/washing steps were repeated until the desired LbL architectures were assembled. Upon obtaining the final multilayers, the composite microparticles were separated by vacuum filtration and dried for $48 \mathrm{~h}$ at $40^{\circ} \mathrm{C}$.

\subsection{Characterization Methods.}

Fourier Transformed Infrared spectroscopy (FT-IR) was used for the investigation of the structural composition of silica/LbL composite microparticles. The measurements were carried out at room temperature using a Bruker Vertex 70 spectrometer (Bruker Optics, Germany) in Attenuated Total Reflectance (ATR) mode, in the range of 4000-600 $\mathrm{cm}^{-1}$, at a resolution of $4 \mathrm{~cm}^{-1}$.

$U V$-vis spectroscopy was used to monitor the sorption of proteins/enzymes and organic dyes, as well as to follow the formation of AgNPs based on their characteristic LSPR effect. The UV-vis measurements were performed with a SPECORD 200 Plus spectrophotometer (Analytic Jena, Jena, Germany).

Atomic force microscopy (AFM) was used to investigate the surface topography of PDMAEMA/SA multilayer films and the characteristics of AgNPs deposited onto silicon wafers. The AFM images were acquired at room temperature using a NTEGRA Spectra (NT-MDT, Moscow, Russia) device.

Streaming potential measurements of the silica/LbL composites were performed using a Particle Charge Detector (PCD-03) (Mütek GmbH, Germany) device. The PCD-03 device was used to determine the $\mathrm{pH}$ at point of zero charge $\left(\mathrm{pH}_{\mathrm{pzc}}\right)$ of the composite microparticles, which is defined as the solution $\mathrm{pH}$ where the potential is $0 \mathrm{mV}$.

\section{Results and Discussion}

\subsection{PDMAEMA/SA Multilayers for Proteins/Enzyme Immobilization}

The charge density of weak polyelectrolytes is an important feature which influences the properties of resulting LbL films. Hence, two types of PDMAEMA/SA LbL films were fabricated on silica microparticles, in which the assembly $\mathrm{pH}$ of PDMAEMA was 5 or 7 , while the assembly $\mathrm{pH}$ of SA was set at 5 . The amount of organic material deposited on silica microparticles as a function of the number of deposited PDMAEMA layers was investigated by a CR staining test (Figure 2A). For both multilayers, CR sorbed amount increased by increasing the number of deposited PDMAEMA layers. The multilayer assembled using PDMAEMA at $\mathrm{pH} 7$ sorbed a higher amount of $\mathrm{CR}$ than the film assembled with PDMAEMA at $\mathrm{pH}$ 5. PDMAEMA is less charged at $\mathrm{pH} 7$ than at $\mathrm{pH} 5$, hence a higher amount was deposited in order to overcompensate the negative charges of SA. Consequently, the multilayer assembled using PDMAEMA at $\mathrm{pH} 7$ contains a higher amount of tertiary amino groups capable to interact with the CR molecules. 

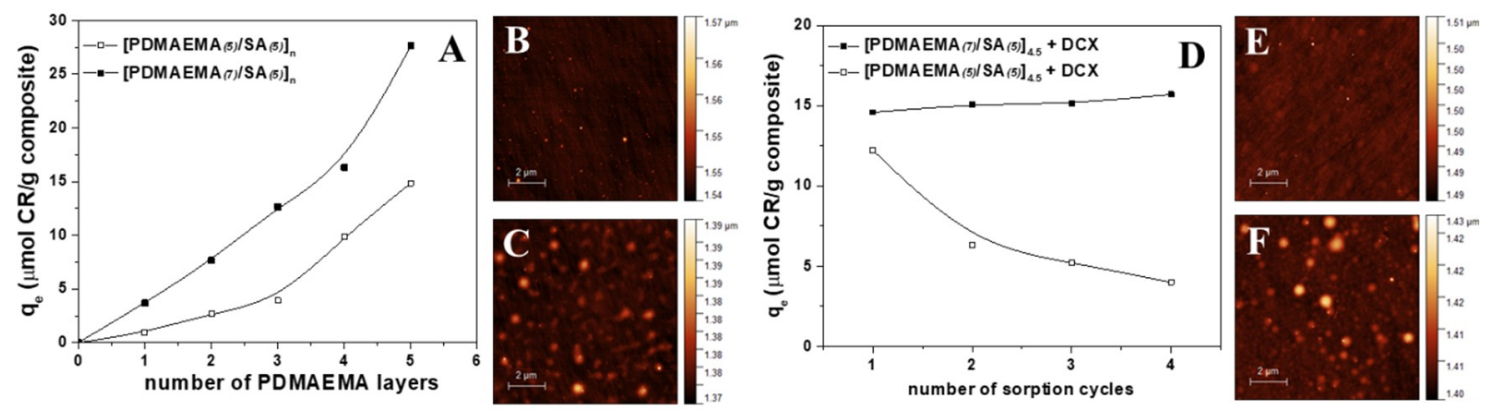

Figure 2. (A) CR sorbed amounts versus number of PDMAEMA layers for the PDMAEMA/SA multilayers deposited on silica microparticles as a function of PDMAEMA's assembly $\mathrm{pH}$. AFM images of [PDMAEMA/SA] 4.5 multilayers assembled using PDMAEMA solutions at $\mathrm{pH} 5$ (B) and pH 7 (C) on silicon wafers. (D) The stability of DCX cross-linked PDMAEMA/SA multilayers in multiple CR sorption cycles as a function of PDMAEMA assembly pH. AFM images of DCX cross-linked [PDMAEMA/SA]4.5 multilayers assembled using PDMAEMA solutions at $\mathrm{pH} 5$ (E) and $\mathrm{pH} 7$ (F) on silicon wafers.

Because both PDMAEMA and SA are weak polyelectrolytes, the resulting LbL films are prone to delamination under environmental factors, such as $\mathrm{pH}$. Hence, to increase the stability of PDMAEMA/SA multilayers, their cross-linking with DCX was tested. DCX is a dihalogenated compound, which can selectively react with the tertiary amino groups of PDMAEMA, with the formation of quaternary ammonium groups. To evaluate the success of the cross-linking reaction, the PDMAEMA/SA multilayers were subjected to successive CR sorption and release (using $10^{-2} \mathrm{M}$ $\mathrm{NaOH}$ solution) experiments. As Figure 2D shows, the LbL film assembled using PDMAEMA at $\mathrm{pH}$ 7 preserved its CR sorption capacity, while the CR sorption capacity of the multilayer assembled using PDMAEMA at pH 5 steadily decreased with the increase of sorption/release cycles. Hence, the LbL assembled using PDMAEMA at pH 7 was more efficiently cross-linked due to the availability of a higher amount of tertiary amino groups in the multilayer than in the film assembled using PDMAEMA at $\mathrm{pH} 5$.

The surface roughness of the non-cross-linked and cross-linked PDMAEMA/SA multilayers was evaluated by AFM imaging (Figure 2B,C,E,F). The root-mean-square roughness values are presented in Table 1. It was found that the films assembled using PDMAEMA at $\mathrm{pH} 7$ were rougher than when PDMAEMA was deposited at $\mathrm{pH}$ 5. At $\mathrm{pH}$ 7, PDMAEMA is less charged, hence it is deposited in a coiled conformation, while at $\mathrm{pH} 5$ its charge density is higher, thus being deposited in a stretched conformation.

Table 1. Roughness values and biomolecules sorbed amounts by non-cross-linked and cross-linked [PDMAEMA/SA]4.5 multilayers assembled on silica microparticles.

\begin{tabular}{|c|c|c|c|c|c|}
\hline Multilayer Type & $\begin{array}{c}\text { Root-Mean-Square } \\
\text { Roughness }\end{array}$ & $\begin{array}{c}\text { qe,PEP } \\
(\mathrm{mg} / \mathrm{g})\end{array}$ & $\begin{array}{c}\text { qe,BSA } \\
(\mathrm{mg} / \mathrm{g})\end{array}$ & $\begin{array}{r}\text { qe,HEM } \\
(\mathrm{mg} / \mathrm{g})\end{array}$ & $\begin{array}{r}q_{e, L Y S} \\
(m g / g)\end{array}$ \\
\hline$\left[\mathrm{PDMAEMA}_{(5)} / \mathrm{SA}_{(5)}\right]_{4.5}$ & $0.81 \pm 0.01$ & $\begin{array}{c}104.74 \pm \\
2.72\end{array}$ & $\begin{array}{c}40.26 \pm \\
1.26\end{array}$ & $\begin{array}{c}6.48 \pm \\
0.65\end{array}$ & $\begin{array}{c}5.86 \pm \\
0.82\end{array}$ \\
\hline $\begin{array}{c}{\left[\operatorname{PDMAEMA}_{(5)} / \mathrm{SA}_{(5)}\right]} \\
4.5+\mathrm{DCX}\end{array}$ & $0.59 \pm 0.02$ & $\begin{array}{c}113.08 \pm \\
1.91\end{array}$ & $\begin{array}{c}50.12 \pm \\
3.64\end{array}$ & $\begin{array}{c}8.18 \pm \\
0.79\end{array}$ & $\begin{array}{c}7.26 \pm \\
1.14\end{array}$ \\
\hline$\left[\operatorname{PDMAEMA}_{(7)} / \mathrm{SA}_{(5)}\right]_{4.5}$ & $1.35 \pm 0.06$ & $\begin{array}{c}87.08 \pm \\
1.42\end{array}$ & $\begin{array}{c}81.9 \pm \\
2.54\end{array}$ & $\begin{array}{c}6.72 \pm \\
1.09\end{array}$ & $\begin{array}{c}2.81 \pm \\
0.52\end{array}$ \\
\hline $\begin{array}{c}{\left[\operatorname{PDMAEMA}_{(7)} / \mathrm{SA}_{(5)}\right]} \\
4.5+\mathrm{DCX}\end{array}$ & $2.23 \pm 0.09$ & $\begin{array}{c}214.21 \pm \\
3.39\end{array}$ & $\begin{array}{c}98.37 \pm \\
0.62 \\
\end{array}$ & $\begin{array}{c}9.03 \pm \\
1.33 \\
\end{array}$ & $\begin{array}{c}4.12 \pm \\
0.95 \\
\end{array}$ \\
\hline
\end{tabular}

Next, the immobilization of PEP (iep = 1.2), BSA (iep = 4.7), HEM (iep = 7.4) and LYS (iep = 11.4) onto the different [PDMAEMA/SA]4.5 multilayers was investigated. It was found that the sorbed amounts depended on the iep of each biomolecule, the highest sorbed amount being for PEP, while 
the lowest for LYS. Also, the cross-linked multilayers exhibited a higher sorption capacity for biomolecules due to the contribution of hydrophobic character of benzene rings of DCX.

\section{2. $C H I / C M C / q P D M A E M A / C M C / C H I$ Multilayers for the Sorption of Organic Dyes}

The LbL assembly technique is very versatile, allowing the deposition of multilayer films using various sequences of polyelectrolytes. Hence, the assembly of a ternary LbL system, with the sequence $\mathrm{CHI} / \mathrm{CMC} / \mathrm{qPDMAEMA} / \mathrm{CMC} / \mathrm{CHI}$, on silica microparticles, was investigated as a function of polyelectrolyte concentration $\left(5 \times 10^{-3} \mathrm{~mol} / \mathrm{L}\right.$ and $10^{-2} \mathrm{~mol} / \mathrm{L}$, with respect to the polymer repeating unit) in the deposition solutions. The success of this LbL system deposition was demonstrated by streaming potential measurements, by "zig-zag" evolution of the $\mathrm{pH}_{\mathrm{pzc}}$ of composite microparticles after each poyelectrolyte deposition step (Figure 3A). The $\mathrm{pH}_{\mathrm{pzc}}$ values for the multilayer deposited at polyelectrolyte concentrations of $10^{-2} \mathrm{~mol} / \mathrm{L}$ were higher than the values for the multilayer assembled $5 \times 10^{-3} \mathrm{~mol} / \mathrm{L}$, showing that the LbL assembly using polyelectrolyte solutions of higher concentration leads to the deposition of thicker layers.
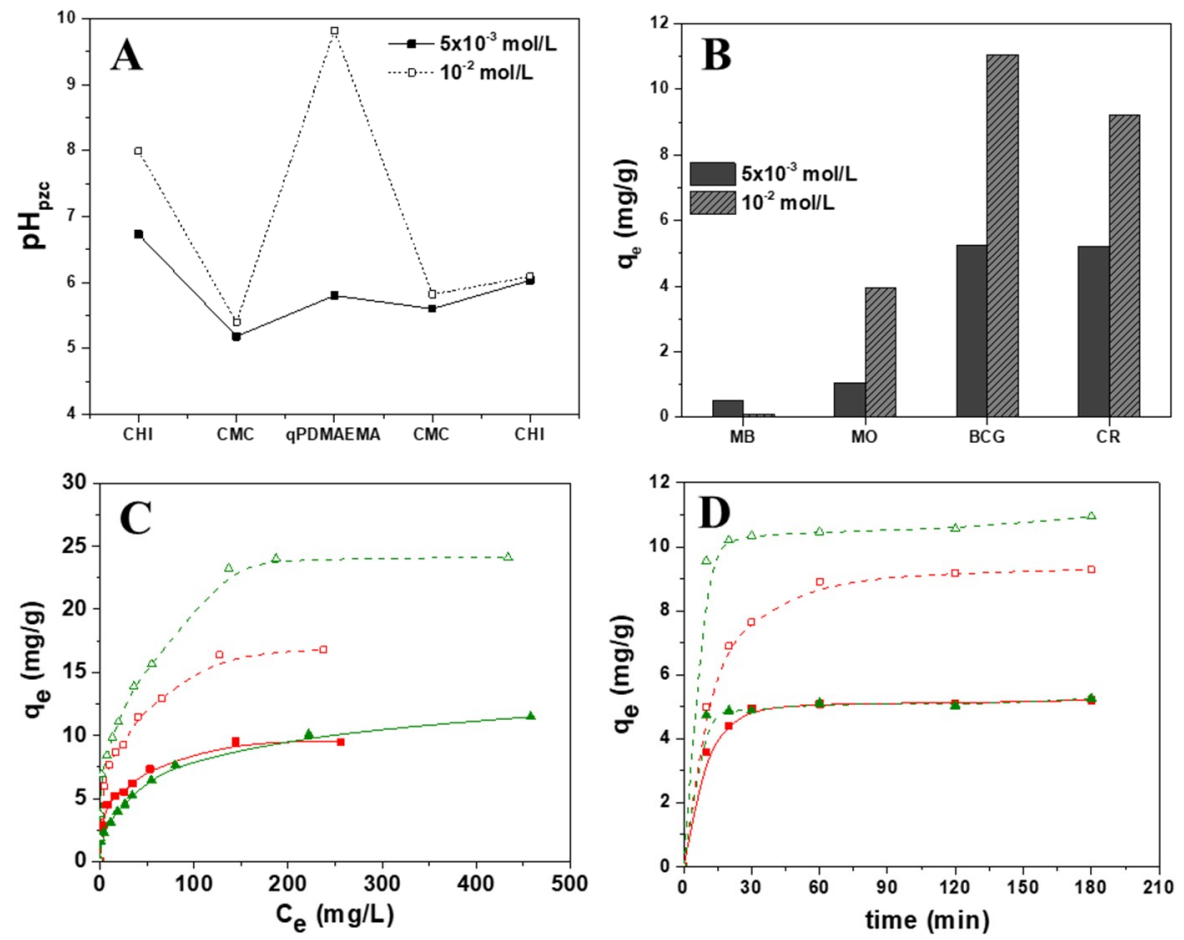

Figure 3. (A) Evolution of $\mathrm{pH}_{\mathrm{pzc}}$ of silica microparticles coated with the $\mathrm{CHI} / \mathrm{CMC} / \mathrm{qPDMAEMA} / \mathrm{CMC} / \mathrm{CHI}$ multilayer after each deposition step as a function of polyelectrolyte concentration in the deposition solutions. (B) Sorption of $\mathrm{MB}\left(\mathrm{C}_{0}=27.58 \mathrm{mg} / \mathrm{L}\right), \mathrm{MO}$ $\left(\mathrm{C}_{0}=51.85 \mathrm{mg} / \mathrm{L}\right), \quad$ BCG $\left(\mathrm{C}_{0}=46.95 \mathrm{mg} / \mathrm{L}\right)$ and $\mathrm{CR}\left(\mathrm{C}_{0}=47.57 \mathrm{mg} / \mathrm{L}\right)$ by the $\mathrm{CHI} / \mathrm{CMC} / \mathrm{qPDMAEMA} / \mathrm{CMC} / \mathrm{CHI}$ multilayers as a function of polyelectrolyte concentration in the deposition solutions. Sorption isotherms (C) and kinetics (D) of BCG (green triangles) and CR (red squares) by the $\mathrm{CHI} / \mathrm{CMC} / \mathrm{qPDMAEMA} / \mathrm{CMC} / \mathrm{CHI}$ multilayers deposited at polyelectrolyte concentrations of $5 \times 10^{-3} \mathrm{~mol} / \mathrm{L}$ (filled symbols) and $10^{-2} \mathrm{~mol} / \mathrm{L}$ (empty symbols).

These LbL systems were tested as sorbents for a library of four organic dyes (MB, MO, BCG and $\mathrm{CR}$ ) (Figure 3B). The lowest sorption capacity was for MB, due to electrostatic repulsions between the positively charged dye molecules and multilayers surfaces. As for the anionic dyes, the multilayer assembled at $5 \times 10^{-3} \mathrm{~mol} / \mathrm{L}$ retained $1.05 \mathrm{mg} / \mathrm{L}$ of $\mathrm{MO}, 5.23 \mathrm{mg} / \mathrm{L}$ of $B C G$ and $5.21 \mathrm{mg} / \mathrm{L}$ of CR, while the LbL film assembled at $10^{-2} \mathrm{~mol} / \mathrm{L}$ retained $3.93 \mathrm{mg} / \mathrm{L}$ of $\mathrm{MO}, 11.06 \mathrm{mg} / \mathrm{L}$ of BCG and $9.22 \mathrm{mg} / \mathrm{L}$ of $\mathrm{CR}$. The influence of dye concentrations and contact time for BCG and CR sorption on the $\mathrm{CHI} / \mathrm{CMC} / \mathrm{qPDMAEMA} / \mathrm{CMC} / \mathrm{CHI} \mathrm{LbL}$ systems assembled at $5 \times 10^{-3} \mathrm{~mol} / \mathrm{L}$ and $10^{-2} \mathrm{~mol} / \mathrm{L}$ 
polyelectrolyte concentrations was assessed by sorption isotherms (Figure 3C) and kinetics experiments (Figure 3D). As it is seen, the BCG and CR sorbed amounts by the constructed multilayers increased gradually by increasing the initial concentrations of dyes in the sorbate and the contact time between sorbent and sorbate. Fitting the sorption data with various empirical models showed that the sorption process was best described by the Freundlich isotherm and Pseudo-second order kinetic models [6].

\subsection{PDMAEMA/CMC Multilayers as Catalysts for AgNPs Synthesis}

The construction of PDMAEMA/CMC multilayers versus the number of assembly steps was investigated as a function of polyelectrolyte and $\mathrm{NaCl}$ concentrations in the deposition solutions. The following assembly conditions were used: (i) $\mathrm{C}_{\text {polymer }}=10^{-2} \mathrm{~mol} / \mathrm{L}, \mathrm{CNaCl}_{\mathrm{Na}}=0 \mathrm{~mol} / \mathrm{L}$; (ii) $\mathrm{C}_{\text {polymer }}=10^{-2}$ $\mathrm{mol} / \mathrm{L}, \mathrm{CNaCl}_{\mathrm{Nal}}=10^{-2} \mathrm{~mol} / \mathrm{L}$; (iii) $\mathrm{C}_{\text {polymer }}=10^{-2} \mathrm{~mol} / \mathrm{L}, \mathrm{C}_{\mathrm{NaCl}}=10^{-1} \mathrm{~mol} / \mathrm{L}$; and (iv) $\mathrm{C}_{\text {polymer }}=5 \times 10^{-3} \mathrm{~mol} / \mathrm{L}$, $\mathrm{C}_{\mathrm{NaCl}}=5 \times 10^{-2} \mathrm{~mol} / \mathrm{L}$. The build-up of PDMAEMA/CMC LbL films on silica microparticles as a function of number of polymer layers deposited was followed by ATR-FTIR spectroscopy (Figure $4 \mathrm{~A})$, taking into account the band at $1728 \mathrm{~cm}^{-1}$, which is characteristic to the $\mathrm{C}=\mathrm{O}$ stretching vibrations of ester groups of PDMAEMA and carboxyl groups of CMC. It was found that the amount of polymers deposited on silica microparticles depended on the polyelectrolyte and $\mathrm{NaCl}$ concentrations in the deposition solutions, as well as on the number of assembly steps. For the LbL systems deposited at a polyelectrolyte concentration of $10^{-2} \mathrm{~mol} / \mathrm{L}$, the absorbance increased with the increase of $\mathrm{NaCl}$ concentration in the order $0<10^{-2}<10^{-1} \mathrm{~mol} / \mathrm{L}$.

Literature shows that materials containing $\mathrm{CMC}$ are able to catalyse the reduction of $\mathrm{AgNO}_{3}$ to AgNPs under ambient conditions [10]. Hence, the interaction of PDMAEMA/CMC multilayers with AgNO3 was investigated as a function of their assembly conditions and the number of deposited layers. The most common method to follow the formation of AgNPs is by UV-vis spectroscopy, due to the appearance of a characteristic absorption peak corresponding to the localized surface plasmon resonance (LSPR) effect [11].
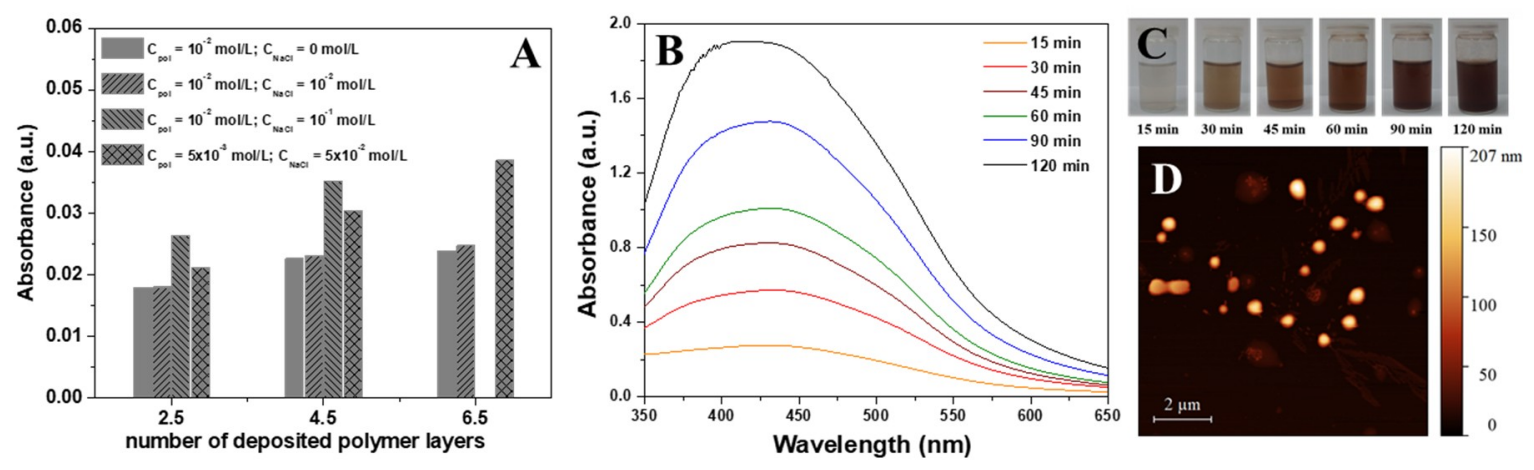

Figure 4. (A) The absorbance of the $1728 \mathrm{~cm}^{-1}$ band versus the number of deposited polymer layers for the PDMAEMA/CMC multilayers, as a function of the LbL films assembly conditions. (B) Kinetic evolution of LSPR characteristic signal and (C) optical images of AgNP as a function of contact time between the [PDMAEMA/CMC] 4.5 multilayer (assembled at $C_{\text {polymer }}=10^{-2} \mathrm{~mol} / \mathrm{L}$ and $\mathrm{CNaCl}_{\mathrm{Na}}=10^{-1} \mathrm{~mol} / \mathrm{L}$ ) and the $\mathrm{AgNO}_{3}$ solution $\left(\mathrm{C}_{\mathrm{AgNO}}=5 \times 10^{-3} \mathrm{~mol} / \mathrm{L}\right)$. (D) AFM image of AgNPs obtained using the $\left[\right.$ PDMAEMA/CMC] 4.5 multilayer (assembled at $C_{\text {polymer }}=5 \times 10^{-3} \mathrm{~mol} / \mathrm{L}$ and $\mathrm{C}_{\mathrm{NaCl}}=10^{-1} \mathrm{~mol} / \mathrm{L}$ ) deposited on silicon wafers $\left(\mathrm{C}_{\mathrm{AgNO} 3}=5 \times 10^{-3} \mathrm{~mol} / \mathrm{L}\right.$; interaction time $\left.=120 \mathrm{~min}\right)$.

It was found that the LSPR peak was only present for the PDMAEMA/CMC films assembled at high $\mathrm{NaCl}$ concentrations, demonstrating that the conformation of polyelectrolytes inside the multilayer architecture is responsible for their catalytic activity. At high salt concentration, the polyelectrolytes are deposited in a coiled conformation, hence more uncompensated carboxylate groups are available to interact with silver ions. The formation of AgNPs was followed as a function of time for the [PDMAEMA/CMC] $]_{4.5}$ multilayer assembled at $\mathrm{C}_{\text {polymer }}=10^{-2} \mathrm{~mol} / \mathrm{L}$ and $\mathrm{CNaCl}=10^{-1}$ 
mol/L. The intensity of the characteristic LSPR peak increased with the increase of contact time between the multilayer and the $\mathrm{AgNO}_{3}$ solution (Figure 4B). Moreover, the optical images of AgNPs suspension show a significant intensification of the brown color as a function of the contact time between the multilayer and the $\mathrm{AgNO}_{3}$ solution (Figure 4C). The size and shape of the AgNPs obtained after $120 \mathrm{~min}$ of contact time between the $\mathrm{AgNO}_{3}$ solution and the [PDMAEMA/CMC] 4.5 multilayer assembled at $C_{\text {polymer }}=10^{-2} \mathrm{~mol} / \mathrm{L}$ and $\mathrm{C}_{\mathrm{NaCl}}=10^{-1} \mathrm{~mol} / \mathrm{L}$ were determined by AFM (Figure $4 \mathrm{D})$. The height AFM images revealed that the AgNPs were spherical and not aggregated. By analysing the height profiles of all nanoparticles in the AFM image, it was determined that the average diameter of AgNPs was $\approx 163 \pm 45 \mathrm{~nm}$, denoting that the formed nanoparticles have a high dimensional polydispersity.

\section{Conclusions}

In this contribution, the fabrication of several multilayer architectures consisting of pristine and benzyl quaternized PDMAEMA and polysaccharides was investigated as a function of the $\mathrm{pH}$, ionic strength and polyelectrolyte concentration in deposition solutions. Furthermore, the potential applications of the obtained LbL systems for immobilization of proteins/enzymes, sorption of organic dyes and as "green" catalysts for the synthesis of AgNPs was studied. Overall, this work provides a comprehensive view on how relatively similar multilayer interfaces can interact with various species (molecules and ions) from their surrounding.

Author Contributions: C.-A.G. and E.S.D. conceived and designed the experiments; C.-A.G. performed the experiments; C.-A.G. analyzed the data; E.S.D. contributed with reagents/materials/analysis tools; C.-A.G. wrote the paper. E.S.D. edited/revised the paper. All authors have read and agreed to the published version of the manuscript.

Conflicts of Interest: The authors declare no conflict of interest.

\section{Abbreviations}

The following abbreviations are used in this manuscript:

$\begin{array}{ll}\text { LbL } & \text { Layer-by-Layer } \\ \text { PDMAEMA } & \text { Poly(N,N-dimethylaminoethyl methacrylate) } \\ \text { qPDMAEMA } & \text { Poly(N,N-dimethylaminoethyl methacrylate) quaternized with benzyl chloride } \\ \text { SA } & \text { Sodium alginate } \\ \text { CHI } & \text { Chitosan } \\ \text { CMC } & \text { Carboxymethyl cellulose } \\ \text { DCX } & \alpha, \alpha^{\prime} \text {-dichloro- } \text {-xylene } \\ \text { PEP } & \text { pepsin } \\ \text { BSA } & \text { bovine serum albumin } \\ \text { HEM } & \text { hemoglobin } \\ \text { LYS } & \text { lysozyme } \\ \text { MB } & \text { methylene blue } \\ \text { MO } & \text { methylorange } \\ \text { BCG } & \text { bromocresol green } \\ \text { CR } & \text { Congo red } \\ \text { AgNPs } & \text { silver nanoparticles } \\ \text { LSPR } & \text { localized surface plasmon resonance } \\ \text { pHpzc } & \text { pH at point of zero charge }\end{array}$

\section{References}

1. Guzmán, E.; Rubio, R.G.; Ortega, F. A closer physico-chemical look to the Layer-by-Layer electrostatic selfassembly of polyelectrolyte multilayers. Adv. Colloid Interf. Sci. 2020, 282, 102197, doi:10.1016/j.cis.2020.102197. 
2. Dragan, E.S.; Bucatariu, F.; Hitruc, G. Sorption of proteins onto porous poly(vinyl amine) multilayer thin films. Biomacromolecules 2010, 11, 787-796, doi:10.1021/bm9014057.

3. Ghiorghita, C.-A.; Bucatariu, F.; Dragan, E.S. Influence of cross-linking in loading/release applications of polyelectrolyte multilayer assemblies. A review. Mater. Sci. Eng. C 2019, 105, 110050, doi:10.1016/j.msec.2019.110050.

4. Mott, R.; Priefer, R. Multilayering as a solution to medical device failure. Colloids Surf. B Biointerfaces 2020, 193, 111154, doi:10.1016/j.colsurfb.2020.111154.

5. Virga, E.; de Grooth, J.; Žvab, K.; de Vos, W.M. Stable polyelectrolyte multilayer-based hollow fiber nanofiltration membranes for produced water treatment. ACS Appl. Polym. Mater. 2019, 1, 2230-2239, doi:10.1021/acsapm.9b00503.

6. Ghiorghita, C.-A.; Bucatariu, F.; Dragan, E.S. Poly(N,N-dimethylamino)ethyl methacrylate/sodium alginate multilayers and their interaction with proteins/enzymes. Int. J. Biol. Macromol. 2018, 107, 15841590, doi:/10.1016/j.ijbiomac.2017.10.030.

7. Ghiorghita, C.-A.; Bucatariu, F.; Dragan, E.S. Novel silica/polyelectrolyte multilayer core-shell composite microparticles with selectivity for anionic dyes. Cellulose Chem. Technol. 2018, 52, 663-672.

8. Ghiorghita, C.-A.; Dragan, E.S.; Bucatariu, F.; Schwarz, D.; Blegescu, C.; Mihai, M. Green synthesis of Ag nanoparticles with uncommon behaviour towards $\mathrm{NaBH}_{4}$ in presence of Congo red using polyelectrolyte multilayers containing sodium carboxymethyl cellulose. Colloids Surf. A 2020, 585, 124157, doi:10.1016/j.colsurfa.2019.124157.

9. Dragan, E.S.; Dinu, I.A. Solution behaviour of progressively quaternized poly(dimethylaminoethyl methacrylate) as a function of charge density. Eur. Polym. J. 2011, 47, 1065-1072, doi:10.1016/j.eurpolymj.2011.02.012.

10. Hebeish, A.A.; El-Rafie, M.H.; Abdel-Mohdy, F.A.; Abdel-Halim, E.S.; Emam, H.E. Carboxymethyl cellulose for green synthesis and stabilization of silver nanoparticles. Carbohydr. Polym. 2010, 82, 933-941, doi:10.1016/j.carbpol.2010.06.020.

11. Jana, J.; Ganguly, M.; Pal, T. Enlightening surface plasmon resonance effect of metal nanoparticles for practical spectroscopic application. RSC Adv. 2016, 6, 86174-86211, doi:10.1039/C6RA14173K.

Publisher's Note: MDPI stays neutral with regard to jurisdictional claims in published maps and institutional affiliations.

(C) 2020 by the authors. Submitted for possible open access publication under the terms and conditions of the Creative Commons Attribution (CC BY) license (http://creativecommons.org/licenses/by/4.0/). 